\title{
Dynamically remembered present: Virtual memory as a basis for the stories we live
}

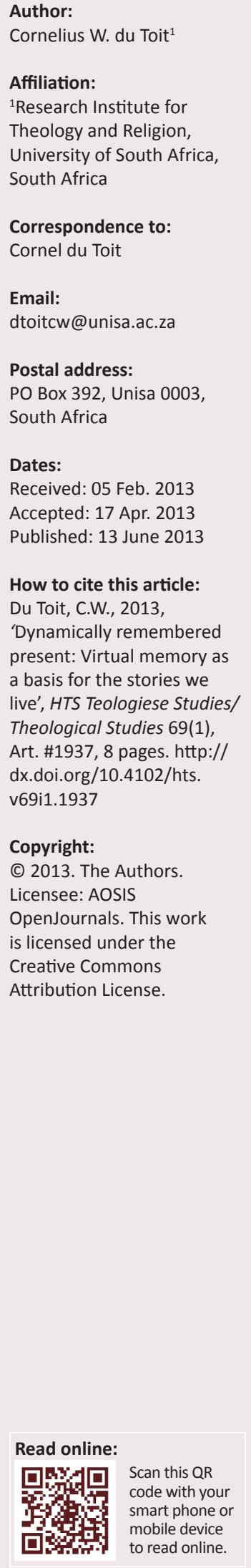

In this article memory was viewed as a crucial key to the discovery of reality. It is the basis of historical research at all levels, hence it is not confined to a function of human consciousness (brain operations): its physical vestiges are discernible in the universe, in fossils, in the DNA of species. Memory inscribes information in various ways. On a human level it is not recalled computer-wise: imagination, emotion and tacit motives play a role in how we remember. The article investigated the way in which memory underlies the operation of every cell in any living organism. Against this background the role of memory in humans and its decisive influence on every level of human life are examined. Gerald Edelman's work in this regard was considered. Marcel Proust's focus on memory is an underlying thread running through his novels, unrivalled in literary history. Some prominent examples were analysed in this article. In light of the foregoing the role of memory in religious experience was then discussed. The virtuality of memory is encapsulated in the statement that we remember the present whilst reliving the past. Memory characterised by virtuality is basic to our autobiographic narratives. The nature of memory determines our life stories, hence our perception of the human self as dynamically variable and open to the future.

\section{Introduction}

Despite extensive research and many publications on memory its actual nature and operation remain elusive. Thus we do not know exactly how the interaction of brain functions and neuron firings trigger consciousness. Human consciousness is the outcome of many factors (such as the subconscious, lived experience, dawning insight, memory and emotion). The various building blocks of human memory can be identified, yet we do not know which comes first and how the process unfolds. It is dependent on information, natural laws, energy, entropy, molecular and chemical interactions, environmental forces, personality, physical make-up and the like. Human memory is unique, but it is not confined to human consciousness.

Memory is consciousness of information - no information, no memory - although information and memory may co-exist without resulting in consciousness of self-consciousness. After all, the physical universe is incomprehensible without information, without 'memory'. This raises questions: What is information, and how do information and 'memory' form part of the cosmos? 'We now need to explain, not the origin of material stuff, but the origin of information' (Davies 2000:62). Conversely, one could ask whether information can exist in the abstract (bearing in mind the physiological roots of thought).

Information is imbedded in every atom. Cosmic 'memory' is imbedded in the evolution of galaxies. We can decipher the history (systematised memory) of organisms. Information determines the identity of phenomena, whether at the atomic level or at the organic level, where complex combinations of diverse elements give birth to new phenomena. A case in point is relational biology: systemic organisation appears to be independent of the material particles constituting the system - it is based on the nature of their interaction. 'Different processes and mechanisms seem to regulate the development and organization of living and nonliving systems' (Perez Velazquez 2009:210).

The genesis and development of life are based on the flow of information from the environment to the organism. 'Life avoids decay via the second law of thermodynamics by importing information, or negative entropy, from its surroundings' (Davies 2000:57). Over long periods that information is biologically fixed in genes. Hence memory is not confined to the human brain: the entire organism - indeed, every cell - is governed by memory. The DNA of every cell contains the phenotypic memory that determines us and even co-determines our behaviour and temperament.

Scholars distinguish between many types of memory. The distinctions are in a sense misleading ${ }^{1}$ in that they are made between entities that are not separate in the brain. Neither do brain areas 
work in isolation. The three main types are short-term, ${ }^{2}$ longterm and sensory memory. Then there are voluntary and involuntary memory; motor memory (like learning to ride a bike); emotional memory; and savings memory. ${ }^{3}$ Distinctions are also made between eidetic and linear, working and reference, childhood (eidetic) and adult (linear), doing and naming, procedural (skill or habits) and declarative ('factual'), and episodic and semantic memory ${ }^{4}$ (see Rose 1993:118-120).

If we were to remember the minutiae of everything we encounter, our memories would be so cluttered with trivial details that we could not possibly retain anything meaningful. For that reason there is a process of perceptual filtering:

... which ensures that, of all the information arriving at one's eye or ears at any given time, only a small portion is actually registered and even briefly remembered ... But one person's relevant information is another's irrelevance. The criteria by which we filter inputs are themselves learned during our own development. (Rose 1993:104, 105)

\section{Memory and emotion (mood)}

Recent neurological research findings show that the brain stores not only information, but also the emotions felt at the time when the information was stored in memory (Damasio 2003:27ff.). Emotional memory appears to be particularly potent and can often be recalled vividly with very little effort. Rose (1993:38) observes in this regard: 'I had learned that cognition cannot be divorced from affect, try as one might.'

Memory is affectively coloured. ${ }^{5}$ When I think about certain events I am nostalgic, sad, embarrassed, scared, enraged all over again. So what colours our recollection of ourselves and others is really just the much spurned emotion, the same emotion that we deny a place in our rationality. Yet my basic feeling about myself (and others) is co-determined by my emotional memory. It co-determines my intuition, perceptions, my very way of thinking about things. Damasio (2003:6) distinguishes between human flourishing and human distress: those that are conducive to the organism's wellbeing (human flourishing) and those that are harmful or cause an imbalance (anything threatening or distressing). The history of evolution shows that emotionality came with the evolution of species.

Some memories are only activated by a certain mood. They only make sense in light of that mood. The mood itself can be linked to a particular time, place, activity and interaction with someone special. Mood has to do with atmosphere, which is connotatively associated with places, people,

2.William James considers short-term memory to be primary - the focus of attention at that moment - as opposed to secondary memory, being knowledge of an earlier state of mind after it has vanished from consciousness (Rose 1993:109).

3.That is retention memory, used to measure how long I retain something (Rose 1993:108). Also see so-called photographic (or eidetic) memory (Rose 1993:102).

4.Episodic memory refers to events or episodes in life and semantic memory is independent of history.

5.That probably accounts for déjà vu experiences and why Christmas, birthdays, and certain places like a lecture room or church building always have a specific atmosphere for us. events and even words. That is why we visit spots in nature that move us. They are associated with affect, hence with specific memories. Certain words, phrases or texts convey a particular atmosphere, especially at a religious level. We recall incidents from memory which, on reliving them, affect our mood. In brief, the brain brings along innate knowledge and automated know-how, predetermining many factors relating to the body (Damasio 2003:205-206). Hence the complexity of consciousness is composed of the person's external world with all its influences, the mental world with its intentionalities, the bodily realm and its many functions. At any given moment consciousness is also co-determined by the influence of memory and by the unconscious (inasmuch as it governs consciousness at that moment), as well as by all the maps that monitor bodily functions and possible imbalances. All these co-determine consciousness either directly or indirectly under the influence of the lymphatic system and active emotions that govern the person's feelings and state of mind.

\section{Memory emerges in consciousness}

Some things I know I know; some things I think I do not know. But there are also things I do not know I know and things that I do not know I do not know. Some of the things I do not (realise that I) know may be buried in the depths of my memory. Only when some stimulus prods my memory do I remember and realise I know it. The reason why some people cannot bear to throw out anything or hate to move to a new home may be attributable to fear of losing hundreds of memory triggers in the process. Old photographs, books, gifts, tools, toys - you name it - trigger memories of things I once owned, did, experienced. Losing such mementoes may mean losing access to those snippets of my past forever.

Memory is more important in an oral than in a literary culture, and more important in a literary culture than in an electronic age in which information can be accessed by pressing a button. We always try to understand the unknown by analogy with the known. That is why language has metaphors. 'Men reason by analogy long before they have learned to reason by abstract characters' (McConkey 1996:140). Memory also works by analogy. What 'evokes' a particular memory is primarily a specific association. It is unclear who actually selects the memory that comes to mind - maybe a homunculus? Maybe me?

Our DNA, which contains information accumulated over millions of years for the sake of effective survival, is insufficient to enable us to live a good life. It has to be augmented with real-life experience stored in memory, which is constantly updated with new experience to afford flexibility in keeping with our personality.

The contents of memory are unfathomable. Some of it is dormant and can probably never be reactivated. But just as we can only think of one thing at a time (see Schrödinger 1992:88), so we can only recall one memory at a time. That is not necessarily the only or most applicable memory. 
Memories are evoked for diverse reasons. Memory of a skill I have learnt is not 'recalled'; it is simply available for use. It functions reflexively, like breathing. That applies to things we learn or memorise: they are instantly available. Of course one may forget details and can check these and memorise them again; but that is different from memories that come to us spontaneously. Memories of experiences we once had, good or bad, usually come to us involuntarily and are activated by some association.

Memory is often activated in a totally different context, in which so many new factors influence that particular recollection that it changes completely. As a rule I am unaware of the changes and have no difficulty identifying with the original recollection. It is my memory, after all. Though the human self is constantly changing, we still experience ourselves as the same person:

We are always what we were; we know ourselves - to the degree that knowledge of the self is possible - through our ever-growing past ... In other words, understanding of our present selves that memory provides us is capable of returning the gift, enabling us to know our earlier selves in a manner that eluded us then. (McConkey 1996:311)

Memory is not merely about information - it concerns meaning:

Thus brains do not work with information in the computer sense, but with meaning. And meaning is a historically and developmentally shaped process, expressed by individuals in interaction with their natural and social environment ... [M]emory is ... a dialectical phenomenon. (Rose 1993:91)

Edelman (1989:30) makes the same point: 'Meanings aren't in the head ... [they are] interactional.'

\section{Understanding of memory expressed in the metaphors of a particular era}

The operation of a complex phenomenon like the human brain can only be expressed metaphorically, but each metaphor applied to the brain is tied to the insights of an era. The brain has not always been regarded as the seat of thought. To Aristotle it was the heart, to the Jews the kidneys and viscera. Memory has been explained by the image of an imprint on wax. In the 2nd century Galen linked thought to the brain, but he used a hydraulic metaphor. ${ }^{6}$ Thereafter the metaphor shifted to electricity (following Galvani's discovery that a frog's legs twitch when subjected to an electric impulse):

the nervous system ceased to be hydraulic and became instead an electrical maze. And within it, the brain became first a telegraphic signalling system and later ... a telephone exchange. (Rose 1993:77)

The same metaphor was used in a more sophisticated way with the advent of computer technology and all its submetaphors (hardware and software, programming, memory). Many references centring on the Turing machine and John

6.This because of the fluid he found in the inner ventricles of the brain: :... early hydraulic memory models had memories stored in the ventricles, and animated by hydraulic memory models had memories stored in the ventricles, and animated by a flowing spirit,
(Rose 1993:76).
Searle's Chinese chamber have become standard in these debates (see Rose 1993:87). But the human brain does not function like a computer - the analogy is false. Neither does it function like a filing system in which memory files are stored to be pulled out and read. The concept of a photographic memory posits the eye as a camera and memory as an 'album' in which the photograph is kept.

The basic metaphor in all these examples is that of connectionism. Examples from artificial intelligence are reductive:

They virtually ignored the fact that the vast majority of nerve cells within complex brains are not in direct communication with the outside world whether by way of sensory input or motor output, but connect internally, receiving messages from and replying to other neurons; that is there is a vast amount of internal processing of any messages that arrive in the brain, and also a great deal of private traffic between these cells (called interneurons), before any external responses are made. (Rose 1993:84)

Unlike a computer, the brain is not determined; it is an open rather than a closed system (Rose 1993:89).

\section{Biological grounds of memory: The cellular level}

If information is the key to understanding the cosmos, then information in the form of memory at the biological level becomes relevant. Francis $\mathrm{Crick}^{7}$ told colleagues that they discovered the secret of life when they stumbled upon the double helix structure. The secret of life was information information which, like memory, had been reliably stored and could be recalled and implemented. But DNA differs from memory. Brain cells have their own, distinctive DNA containing instructions for the functioning of the specific area in which those cells operate. Memory is a product of the action and interaction of actual neuron cells.

Whereas DNA is fixed and conservative (the selfish gene) because any change or copying error could cause a mutation with possibly catastrophic consequences, a new memory is an original creation with unforeseen positive and/or negative results. Experience has a biological impact on the person. 'And long-term memory involves gene activity and protein synthesis that lead to new synaptic connections being made, and the pruning of some synaptic connections' (Wolpert 2009:133; cf. Rose 1993:183-185). It would be reductive to maintain that memory is simply protein synthesis or electro-chemical processes. It is a product of emergent processes that took place over millions of years in unique, unrepeatable fashion. If we could turn back the clock some 4.8 billion years to the beginning of the evolution of life, it would not follow the same course the second time round.

7.Watson, Crick and Wilkens, who were awarded the Nobel Prize for deciphering the structure of DNA in 1962, indicated that DNA was the aperiodic solid to which Schrödinger had referred (Regis 2008:40). This established information as a metaphor for life: '... their introduction of the information metaphor to the as a metaphor for life: ... their introduction of the information metaphor to the repertoire of biological discourse was a stroke of genius' (Regis 2008:40). NeumannHeld (2006:250) avers that the information idiom has been applied consciously 'with all its connections to mathematics, logic, crypto-analysis, linguistics, computers, operations research, and weapons systems ... as a means of framing the "coding problem".' This introduced the notion of control into genetic specificity. It also became the discursive framework for molecular thinking (Neumann-Held 2006:251). 
Life, the end product, is the aggregate of building blocks that went through the right processes at the right point. Nor does it mean that factors like time, chance and variety can be afforded divine or supernatural status. ${ }^{8}$ Life is more than its building blocks, than chance, variety and time, even though it cannot be fathomed without these. We cannot reduce either 'downwards' or 'upwards'.

Like all organs in the human body, the brain has a long evolutionary history. Our forebears did not wake up one morning and remember last night for the first time. We are born with about 100 billion brain cells ${ }^{9}$ capable of some 100 trillion connections. But because the manner in which neuron connections are made is unpredictably endless, the possibilities are limitless. And that refers only to intra-mental connections. In addition there is interaction with a limitless outside world, and nerve cells communicate with one another: 'But how this enormous society of brain cells talking to each other can give rise to all our thoughts, emotions, movements, and even consciousness still remains a mystery' (Wolpert 2009:119).

Each cell in the human body (except red blood cells that have no nucleus) is a memory bank containing the entire organism's information. ${ }^{10}$ DNA stores the information that permits all bodily functions. That information may be regarded as recorded memory. After all, information and memory are complementary. Without memory information is lost; without information, or with false information, memory is worthless. Of the 3 billion odd basic pairs accommodated in the 46 human chromosomes $89 \%$ is junk, but they probably contain the primeval memory in which aeons of evolutionary history are imbedded. Maybe future biologists will decipher some of this information. It includes information about human genetic lines, migration patterns, diseases and diet. Mutations in the mitochondrial genome could tell us which ethnic groups are related and which are not. It can reveal the migration patterns a group followed and it has been used to trace the human lineage to Africa (see Oppenheimer 2003:45ff.).

\section{Gerald Edelman}

In 1972 Gerald Edelman was awarded the Nobel Prize for medicine for his work on immunology. In Neural Darwinism (1987) he works out his theory of memory, which he sees as changing dynamically in interaction with the environment. The remembered present (1989) deals with his theory of

8.Edelman's Neural Darwinism deals with this subject. In his The remembered present (Edelman 1989:xvii) he writes: 'My main focus was on perceptual categorization as it related to memory and learning. I proposed that these functions could be understood in terms of "neural Darwinism" - the idea that higher brain functions are mediated by developmental and somatic selection upon anatomical and functional variance occurring in each individual animal.

9. Rose (1993:50-51) indicates that apart from the $10^{14}-10^{15}$ brain cells (neurons), each cell is imbedded in up to ten smaller glia cells that play a supportive, nourishing role.

10.Our body records all diseases that attack us and is ready to release antibodies instantly in the event of a renewed attack. The immune system in particular activates cellular major and viruses play a majory, in we. Our adaptive imm milty depends mainly on adaptive lymphocytes, of which the body contains millions. Antibodies bond with bacterium or virus and mark it for destruction by macrophages. Thus the body builds up its immunological memory (Wolpert 2009:170ff.). consciousness and memory as re-entry. Variability ${ }^{11}$ and re-entry go hand in hand. The size of the brain allows such variation that certain outcomes at a conscious level are unpredictable. But according to TNGS (Theory of Neural Group Selection) just as much happens at an unconscious level. This theory posits that the brain categorises signals from the environment by selecting appropriate (to the brain) neural maps. The selection is made through a critical process of re-entry:

Neural systems capable of this mapping can deal with novelty and generalize upon specific programming, they are selforganizing and do not invoke homunculi. Unlike functional systems, they can take account of an open-ended environment. (Edelman 1989:31)

There are numerous parallel re-entrant connections between individual cells and neuron groups, which makes the entire brain interactive. But Edelman's TNGS insists that the world is not organised like a magnetic tape for a Turing machine or a universal computer (Edelman 1989:24).

To Edelman (1989:109ff.) memory is a matter of recategorisation. Because the word is used so widely (with reference to anything from molecular to learning events) it has to be re-specified in each instance. I repeat, memory is not a case of calling up data from a given storage space. That is the way computers work, but not the brain. The information that is called up is no less dynamically changeable:

$[I] \mathrm{n}$ rich nervous systems, memory is the specific enhancement of a previously established ability to categorize. This ability is procedural, and it emerges from the continual dynamic changes in synaptic populations and global mappings that allowed a particular categorization to occur in the first place. (Edelman 1989:109)

Edelman points out that memory is not placed in the brain as a content, but as a re-entrant strengthening of synaptic connections, which, through reinforcement during the retelling, can reach the level of long-term potentiation that would create what we call permanent memories. The content of the memories is the way to retrieve them (via association) and the process of retrieving the memories is the content of the memories. What happens as you begin to think of the memory is that your brain activates certain neuronal groups, which activation helps you to create the memory you desire. It also helps you to facilitate its later recollection.

Human consciousness is linguistic in nature ${ }^{12}$ (it can only be expressed in language) and language imbues the sensory world with meaning. Edelman (1989:19) cites examples of forms of consciousness relating to direct perception, images, and language. But each form of consciousness presupposes that it can be captured in language. We know that language is associated with the brain areas of Warnick and Broca, but how consciousness is recorded linguistically in the physical brain and how this differs from non-linguistic recording of consciousness in animals we do not know. Animals' brains

11.Boyer (2010:45) writes: 'The raw material of evolutionary processes is variation. No variation, no natural selection.'

12.Edelman (1996:18) sees consciousness as individual in animals and subjective in humans. 
do record sensory impressions, otherwise they would be unable to interact with the world, but how it happens (what kind of mind maps) is still a question, related to the qualia problem. ${ }^{13}$

Evolution depends on chance and selection. Over millions of years the selections leading to successful adaptation and survival have been recorded in our DNA. Still every organism, equipped as it is with a sophisticated, adapted body, constantly has to choose. Consciousness has to remain open to interaction with a dynamically changing environment. Hence Edelman (1989:30) deviates from principles like 'instructionism' of the mechanistic type. ${ }^{14}$ The choices the brain makes are determined synaptically: 'Such a process leads to differential modification of synapses and the selection of particular neuronal groups on the basis of individual experience in an open-ended world or environment' (Edelman 1989:31).

The title of his book, The remembered present, puts it in a nutshell: the biology that creates consciousness does so by recovering the past in the present, comparing the past with the present, and re-storing the modified conception. At each moment the perception of the now is compared to the perception of the past and a new perception of the past is laid down in one's neuronal groups. Edelman leads us to see that we always live in the remembered present.

There is no such thing as consciousness per se, without content. All consciousness is consciousness of something. Since it is always consciousness of something, it is dual in character (Navickas 1976:82). To be conscious of something, an object, is to be conscious of something outside myself (a non-self) independent of thought (consciousness). Consciousness is relational. There is a whole world in my consciousness: no world, no mental world. In fact, memory is activated by my interaction with a continually shifting world, from which new questions, challenges and demands emerge. The memory that arises involuntarily through association, or whatever other mechanism, is usually intended to shed light on the present situation. The present world in which I am situated, and especially the way I speak and think about it, probably triggers the relevant memory.

Memory is more than fixed content stored somewhere in the brain. One way of looking at it is to see certain aspects of memory as if it has a 'personality' of its own, which grows and changes. Is that not precisely what creative writers and poets regularly experience - that a poem writes itself, a story takes off on a tack of its own, that the story writes me rather than I write the story? 'The work in process becomes the poet's fate and determines his psychic development. It is not Goethe who creates Faust, but Faust which creates Goethe' (McConkey 1996:161).

13.When I see a yellow rose I do not know objectively that the yellow I see is exactly the same as the yellow someone else sees. I do not have access to that person's subjective experience. This applies to all our perceptions. We can describe them, but we cannot convey our experience to another person. Edelman (1989:166-167) sees this as 'the various subjective experiences, feelings, and sensations that
constitute or accompany awareness.'

14.'Reeke and I have also rejected machine functionalism or, as we called it, "instructionism"' (Edelman 1989:30).
A watered down conception of memory probably derives from equating it with memorisation. A person with a good or even a photographic memory is someone who remembers and renders things accurately. A good memory is like a good witness who does not read her own interpretation into events, distorting or adapting the actual events. In this respect memory and creativity are not connected. Creativity, after all, is about something new, some unexpected, unpredictable development, whereas memory recalls what has already happened, something past, déjà vu. But what we separate is not separated in the brain. Thus creativity may be seen as memory in a playful mood. Images, ideas, memories, experiences, whatever comes to mind are appraised in a split second, tried out until something new emerges - and if it works, I will elaborate it into a new creation, a new idea, story or metaphor.

Naturally, we are not at the mercy of such boundless creativity that nothing is predictable or knowable in advance. Creativity is the dynamics of every new game, which does not mean that all rules go overboard. To express things differently does not imply breaking grammatical rules. That is where the transcendental subject comes into it, when I apply order, regularity, categories and all the other Kantian a priori certainties to reality without being able to read them there in advance. And reality permits this, just as mathematics displays symmetry with reality that reaches aesthetic heights.

But I am not just the transcendental subject superimposing structures on reality. I am also the blind man who has to feel my way in an unknown world and, like a researcher, must let myself be guided by reality. I am the student learning what others know already; the artisan learning something new about my trade every day.

\section{Marcel Proust}

The 3125 pages of Proust's Remembrance of things past contain 1120 references to memory (Bogousslavsky \& Walusinski 2009:135). In world literature, it is a unique novel on autobiographic memory. ${ }^{15}$ Proust's focus on memory goes way beyond the much quoted reference to the madeleine pastry that evokes a string of youthful memories. Proust was influenced by the neurosurgeon Dr Paul Sollier's research into involuntary memory and actually went to him for neurological therapy. Sometimes we feel that memory keeps eluding us. However, inability to remember something is not caused by destabilisation of memory, provided that involuntary memory is functioning properly. Sollier identifies six basic factors in good memory: stimulus intensity, duration, repetition, attention, coexisting emotion and will (Bogousslavsky \& Walusinski 2009:133). Many of his patients suffered from what we now call post-traumatic stress syndrome. Sollier describes the experience of intense involuntary memory:

15.There are ten basic memory themes in Proust's work: involuntary memory; voluntary memory; affective memory; the constructive and deconstructive process of memory; reality-memory discrepancy; the phenomenology of memory and of memory; reality-memory discrepancy; the phenomenology of memory and
remembering; habitude; forgetting; memory processing into patterns; the role of time in memory; and memory dysfunction (Bogousslavsky \& Walusinski 2009:135). 
Re-experiencing ... is not only the appearance of an image in the field of consciousness, but the appearance is so clear and accompanied by such a precise and intense reproduction of the state of personality of the subject at the time of the initial impression, that the subject again believes they are going through the same events as before. (Bogousslavsky \& Walusinski 2009:134)

Sollier stresses the decisive role of emotion in involuntary memory and the relatively minor role of human volition in the process:

Our will really plays a trivial role in the evocation of memories, and it is an illusion to believe that it is under the influence of free and voluntary efforts that this takes place. (Bogousslavsky \& Walusinski 2009:134-135)

Involuntary memory is a common phenomenon and not confined to post-traumatic stress syndrome. It includes all sorts of religious and personal experiences, especially ones that are emotionally coloured, even those that are not ordinarily associated with emotion (jealousy, suspicion, vengefulness, acute embarrassment, self-reproach, remorse, etc.). Memory is governed by a particular emotion. Someone who is intensely jealous or suspicious of underhand scheming ransacks her memory and every interaction with the suspect party.

By way of example we look at Proust's Remembrance of things past, more particularly the volume where this aspect features most prominently: The captive. The background is the narrator's growing suspicion that his partner, Albertine, is cheating on him. Proust describes the development of this train of memory:

Travelling lazily upstream from day to day, as in a boat, and seeing appear before my eyes an endlessly changing succession of enchanted memories, which I did not select, which a moment earlier had been invisible, and which my mind presented to me one after another, without my being free to choose them, I pursue idly over that continuous expanse my stroll in the sunshine. (Proust 1949:105)

As the memory unfolds, he is brought up sharply by the following experience:

$[M] y$ thoughts, which hitherto had been sailing blissfully over these untroubled waters, exploded suddenly, as though they had struck an invisible and perilous mine, treacherously moored at this point in my memory. (Proust 1949:105-106)

Past events which had been dismissed as insignificant and pushed to the back of memory or relegated to oblivion suddenly become momentous as we struggle to reconstruct the bygone episode: 'How many persons, cities, roads does not jealousy make us eager thus to know?' (Proust 1949:108). We visit and revisit the little we recall in the hope of discovering some clue: '... we turn over and over incessantly in our cage the most trivial utterances', '[trying] to remember whether she had said this or that, at what moment, in response to what speech of mine, to reconstruct the whole scene of her dialogue ...' (Proust 1949:120,121). But here memory often fails us and imagination is quick to fill the gap:

... our jealousy ransacking the past in search of a clue can find nothing; always retrospective, it is like a historian who has to write the history of a period for which he has no documents; always belated, it dashes like a mad bull to the spot where it will not find the proud and brilliant creature who is infuriating it with his darts and whom the crowd admires for his splendour and his cunning. (Proust 1949:193)

Proust is aware that his behaviour is determined by his background, his childhood home, and that these memories are etched into his memory and surface unconsciously in his actions. But what emerges powerfully at this point is the jealousy that has taken hold of him and whose origin he recognises:

No doubt, as each of us is obliged to continue in himself the life of his forebears, the balanced, cynical man who did not exist in me at the start had joined forces with the sensitive one, and it was natural that I should become in turn what my parents had been to me. What is more, at the moment when this new personality took shape in me, he found his language ready made in the memory of the speeches, ironical and scolding, that had been addressed to me, that I must now address to other people, and which came so naturally to my lips, whether I evoked them by mimicry and association of enchantments or the reproductive power had traced in me unawares, as upon the leaf of a plant, the same intonations, the same gestures, the same attitudes as had been adopted by the people from whom I sprang. (Proust 1949:139-140)

There is also the role of dreams. How often do we not wake up with the most vivid images in our minds, which evoke all sorts of recollections, prompting us to search our memory for further examples (see Proust 1949:158ff.).

\section{Memory and religious experience}

Christianity is a mnemonic religion, peppered with rituals recalling the past. God's covenant with humankind is pivotal: that promise is constantly evoked and experienced. The memory of the covenant underlies the expectation that God will once again deliver us. Easter and the Eucharist ritually re-enact the salvific events and the experience of redemption is relived in the liturgical rendering. Memory and faith can actualise redemption as a present reality. This is complemented by the granting of forgiveness, which absolves the penitent from the sinful past. God's renewing activity erases the sinful memory and bad conscience, which shackle the believer to the law and concomitant doom. Via memory both the Old and the New Testament invoke God's salvific acts, in which the deliverance from Egypt and Christ's crucifixion are focal. These acts are recalled differently each time and applied to the present context. That affirms the interdependence of memory, imagination and their integration with individual personal experience. John Dewey (1920) puts it thus:

The past is recalled not because of itself but because of what it adds to the present. Thus the primary life of memory is emotional rather than intellectual and practical. (p. 16)

Religion without emotion is inconceivable. Religious experience is intense because of the powerful emotions involved: danger and deliverance; guilt (shame) and absolution; rejection and acceptance. The fascinating thing 
about human experience is that it often comes into its own only when it is recounted. In the heat of the moment we often act reflexively and only appreciate the full impact of what happened in retrospect when we remember it. Only when we 'unpack' it in language do we realise what a close shave we had in real life: '... the conscious and truly human experience of the chase comes when it is talked over and re-enacted by the camp fire' (Dewey 1920:16). But in rendering the event in language we are already deviating from the actual events. We rearrange them, speculate about cause and effect, and ascribe heroism or a miracle to the outcome. In this regard Dewey (1920:17) comments: 'Incidents are rearranged till they fit into the temper of the tale.' Our stories are co-determined by imagination: '... men are governed by memory rather than by thought, and ... memory is not a remembering of actual facts, but is association, suggestion, dramatic fancy' (Dewey 1920:20).

Tavis's views on religious experience should be read in this light. Tavis (2009:48) shows that all religious experience is grounded in ascription of divine agency to the person's experience. She stresses the role of language, tradition and culture in constituting experience (Tavis 2009:56). She demonstrates how the different conceptions of the Eucharist in the Catholic and Protestant traditions lead to different ways of recalling Christ's salvific act, triggering different experiences (Tavis 2009:144ff.). Often the way we remember and the way imagination and emotion feature in our stories make such an impact that an individual story grows into the narrative of a group, culture, cult or tradition. 'The story becomes a social norm. The original drama which re-enacts an emotionally important experience is institutionalised into a cult. Suggestions previously free are hardened into doctrines' (Dewey 1920:21).

But it is a two-way process: experience gives rise to imaginative narration in which memory is adapted to suit the story. Later generations fall back on these stories, which trigger new experiences when integrated with their own experience. Hence memory is pivotal in religion, and the way it is articulated in dogma and liturgy gives rise to diverse religious experiences.

\section{Virtual memory: A foundation for the stories we live}

We remember the present whilst reliving the past. So much of consciousness is filled with reliving the past. If I do not remember the eternal now in which I live, I will not have a past to live in. Now is a fleeting moment, over as soon as it happens. To grasp all the serial nows that make up my life I fall back on memory. ${ }^{16}$ It would therefore be more correct to say that we live virtually in our memories rather than now (in reality). Ontologically that makes the contents of the mind purely virtual. It makes time, my time, my life virtual. My lifetime only becomes real in my memory when

16.McConkey (1996:80) quotes Thoreau: 'Above all, we cannot afford not to live in the present. He is blessed over all mortals who loses no moment of the passing life in remembering the past.'
I reflect on it and retrospectively reconstruct and experience its events with a view to the future. But the future, too, comes to us in light of the past. Past experiences determine future action. The way I remember them determines what I will avoid, pursue, trust, and commit myself to. Strictly speaking God only lives in the past, for a God who already knows everything that will happen is condemned to an inexorable déjà vu. If I already know the future in minute detail, it lapses into the past tense and I have no authentic future. (Hence reformed theology posits a super-temporal or extra-temporal God, thus obviating paradox. But a God who is pure Spirit in omniscient mode is no less susceptible to paradox.)

McConkey (1996) cites William James, who:

speaks of the specious present, our intuition of living in the present moment of time. Beyond its borders extends the immense region of conceived time, past and future, into one direction or another of which we mentally project all the events which we think of as real. Our apprehension of any real event of the passing moment is given coherence, made acceptable rather than fantastic, by the memories we impose upon it. (p. 66)

Hegel ([1952] 1979) puts it thus:

Reason, as it immediately comes before us as the certainty of consciousness that it is all reality, takes its reality in the sense of the immediacy of being, and similarly, the unity of the ' $\mathrm{I}$ ' with this objective being in the sense of an immediate unity, in which it has not yet divided and reunited the moments of being the ' $\mathrm{I}$ ', or which has not yet discerned them. (pp. 146-147)

Here Hegel makes an important observation: in my perception of something I approach it as a sensorily observable object confronting the self (' $\left.\mathrm{I}^{\prime}\right)$, but what reason actually does is to mentally transform the sensory quality of the object or thing into a notion: '.. it maintains, in fact, that it is only as notions that things have truth' (Hegel [1952] 1979:147). This probably relates to James's distinction between primary and secondary consciousness. Edelman reminds us that in humans (in contrast to animals, who have only primary consciousness) primary and secondary consciousness coexist and have different relations to time. 'Higher order consciousness is based not on ongoing experience, as is primary consciousness, but on the ability to model the past and the future' (McConkey 1996:50).

The internet is a metaphor for global memory. Memory chips become an extension of our own memory where we deposit our experience. People 'eternalise' everyday trivia on Facebook. In religious terms an appealing alternative view of the hereafter is living on for ever in God's memory (Ricoeur 2009:44). Modern views of the self are marked by virtuality. ${ }^{17}$ Eminent philosophers ponder the extent to which they will live on (virtually) in the writings they leave. Science fiction films like Matrix ask how we know that all existence is not purely virtual, a program.

Thus memory changes dynamically in the course of life. Some memories are so vivid, they may have happened

17.For the development from a phonocentric to a logocentric to a virtuocentric culture and its influence on our self-perception, see Du Toit (2004:4-7, 17ff.). 
yesterday and to us they are indelible. Others are adapted, often without our realising it because they grow along with us. We live in stories that are made possible by memory. But how do we remember our own story? Like historians interpreting facts according to some ideology? Memory is not factually neutral or necessarily factually correct, because life itself cannot be objectified in that fashion. Underlying the 'facts' we remember are emotion, colour and timbre. That is what makes it my memory, because it resonates with my experience.

In evolutionary terms one could say that memory exists to make us adapt and function more effectively in our environment. It means memory has to accord with the moment and my immediate situation with its demands. That may seem very functionalist and may reduce memory to pragmatism. Yet experience teaches us that what makes memory unique is not so much its functionality but the meaning it has for us. Because that meaning is affectively coloured it concerns the smell of a room, the taste of a sweetmeat eaten in a particular situation with its distinctive affective associations: the sweetmeat opens up a whole world. That makes memories retrievable but not repeatable. And that is why they are adapted, involuntarily, unconsciously. Is that not what makes life exciting?

\section{Acknowledgements Competing interests}

The author declares that he has no financial or personal relationship(s) which may have inappropriately influenced him in writing this article.

\section{References}

Bogousslavsky, J. \& Walusinski, O., 2009, 'Marcel Proust and Paul Sollier: The involuntary memory collection', Schweizer Archiv für Neurologie und Psychiatrie 160(4), 130-134.

Boyer, P., 2010, The fracture of an illusion: Science and the dissolution of religion, Vandenhoeck \& Ruprecht, Göttingen.

Damasio, A., 2003, Looking for Spinoza: Joy, sorrow, and the feeling brain, Harvest Books, London. PMCid:187761

Davies, P., 2000, The 5th miracle: The search for the origin and meaning of life, Simon \& Schuster, New York.

Dewey, J., 1920, Reconstruction in philosophy, Quinn \& Boden, Rahway. (Kindle version).

Du Toit, C.W., 2004, 'Technoscience and the integrity of personhood in Africa and in the West: Facing our technoscientific environment', in C.W. du Toit (ed.), The integrity of the human person in an African context: Perspectives from science and religion, pp. 1-46, Research Institute for Theology and Religion, Pretoria.

Edelman, G., 1989, The remembered present, Basic, New York.

Edelman, G., 1996, 'Bright air, brilliant fire: On the matter of mind', in J. McConkey (ed.), The anatomy of memory: An anthology, pp. 47-54, Oxford University Press, New York.

Hegel, G.W.F., [1952] 1979, Phenomenology of spirit, Clarendon, Oxford.

McConkey, J., 1996, The anatomy of memory: An anthology, Oxford University Press, New York.

Navickas, J.L., 1976, Consciousness and reality: Hegel's philosophy of consciousness, Nijhoff, The Hague. http://dx.doi.org/10.1007/978-94-010-1366-6, PMid:1259424

Neumann-Held, E.M., 2006, 'Genes - causes - codes', in E.M. Neumann-Held \& C. Rehmann-Sutter (eds.), Genes in development, pp. 238-271, Duke University Press, London.

Oppenheimer, S., 2003, Out of Africa's Eden: The peopling of the world, Bell, Johannesburg. PMCid:165027

Perez Velazquez, J.L., 2009, 'Finding simplicity in complexity: General principles of biological and nonbiological organization', Journal of Biological Physics 35, 209221. http://dx.doi.org/10.1007/s10867-009-9146-z, PMid:19669573, PMCid:2710456

Proust, M., 1949, The captive, part 1, Chatto \& Windus, London.

Regis, E., 2008, What is life? Investigating the nature of life in the age of synthetic biology, Oxford University Press, Oxford.

Ricoeur, P., 2009, Living up to death, University of Chicago Press, Chicago. http:// dx.doi.org/10.7208/chicago/9780226713502.001.0001

Rose, S., 1993, The making of memory, Bantam, New York.

Schrödinger, E., 1992, What is life?, Cambridge University Press, New York.

Tavis, A., 2009, Religious experience reconsidered: A building-block approach to the study of religion and other special things, Princeton University Press, Princeton.

Wolpert, L., 2009, How we live and why we die, Faber \& Faber, London. 